extra back premises have been designed specially to include additional scientific research rooms with electrically equipped workshops, a dark-room, and extensive storage accommodation.

All the three galleries have been designed to include complete accuracy with artistic merit, and special attention has been paid to simplicity, so that each exhibit can be easily understood by children. Possibly the Churchill gallery is the most striking, for here is a display far ahead of its counterpart in the British Museum, London.

In an adjacent gallery is the botany section, presented in 14 specially designed flower painting displays set in their various botanical groups and painted by Joy Adamson, the wife of a Kenya game warden. Special features of this gallery are panelled walls of indigenous Kenya timbers presented by the Forest Department, and a round table inlaid with 50 different species of Kenya woods.

In the Gandhi Hall, approximately three-quarters of the exhibits have been devoted to geology. This exhibition has a practical commercial and industrial significance and has proved invaluable to prospectors and to economic research. There is also a section concerning the straight geology of East Africa.

The most important exhibits in the palaeontological section are of the Miocene and Pleistocene eras-25 million and one million years ago respectively-in the history of East Africa. Of outstanding importance in the Miocene exhibit is that illustrating the famous fossil apes of many genera and species from Rusinga Island in Lake Victoria and adjacent sites, and including the cast of the unique Pro-Consul skull.

In the Aga Khan Hall the ethnological section has been devoted almost entirely to a collection of African weapons and arts and crafts, the nucleus of this exhibit being supplied from a collection presented by Sir Frederick Jackson, once Governor of Uganda and a celebrated field naturalist. Lack of space allows only eight tribes out of Kenya's 57 to be shown at one time, and this exhibit is continually being changed. Because of the rapid disappearance of African tribal customs, this collection, together with Joy Adamson's paintings of Kenya tribesmen in their ceremonial and war dress, will in years to come have considerable ethnological value.

The prehistoric section fills the second half of the Aga Khan Hall. The central block of cabinets carries the story of the Stone Age cultures in East Africa from a million years ago to A.D. 50o. On the walls there is a series of exhibits illustrating examples of prehistoric art in East Africa, some dating as far back as 25,000 years ago. One end of the hall is completely taken up with a large reproduction of part of the wall of the famous painted site at Cheke in Tanganyika, and on it are reproduced about 300 of the original paintings showing all the various super-impositions of the different art styles.

The Coryndon Museum, now considered one of the most important museums south of the Sahara, is still incomplete. Its story of continuous development and expansion, since its humble beginning as Nairobi's museum 40 years ago, seems likely to continue. It is undoubtedly achieving its purpose and is a great attraction to visitors from all over the world. Its doors are open to all races, and many travel vast distances to learn about the land in which they live.

\title{
Rhodesia University College
}

THE University College will be built on the Mount Pleasant site in Salisbury. The City of Salisbury has granted to the Inaugural Board additional land adjacent to the original Mount Pleasant site, bringing the total area of the College site to 458 acres. The College will be granted facilities for teaching and research in the projected Botanical Gardens near to the University site and at a veterinary research station, and land can be given to the College for a teaching and experimental farm of about 1,000 acres on a suitable area to be made available 
for the purpose. Land on the 250-acre site on which the new Salisbury Native Hospital is being erected will be made available for the needs of a Medical School.

A basic principle in the planning of the site, buildings and facilities will be that there should be no discrimination on racial grounds between categories of students.

Progress has been made in drafting a constitution for the College in a form which will ensure its autonomy. It is the intention to petition Her Majesty the Queen for the University College to be incorporated by Royal Charter.

The Inaugural Board has applied to the University of London for the admission of the College into special relationship with the University. The Senate of London University has signified its willingness to accept the College into this relationship, subject to the receipt of information satisfactory to the University in regard to the constitution and proposed development of the College. Degrees conferred on students of the University College will be those of the University of London, courses at the College being based on syllabuses adapted to local opportunities and needs in consultation between the College itself and the University authorities.

The College will begin by establishing the basic faculties of Arts and Science, and the Principal has already discussed with the University of London requirements for the admission of students to the College and to these faculties. As soon as possible faculties of Agriculture and Medicine will be established.

The initial building and equipment programme, staffing and other preparations will take at least two years to complete, but every effort will be made to open the College for teaching by March 1956 .

\section{Archaeological Museum in the Gold Coast}

A GRowING and eager interest in its own past is being manifested in the Gold Coast, evidence of which may be found in the activities of the Gold Coast and Togoland historical society (see Africa, xxiv. 2, pp. 163-4) and in the reception given to the lecture delivered at Cape Coast in April last by Professor Lawrence, Professor of Archaeology in the University of the Gold Coast. Interest in archaeology is being stimulated and guided by the development of the National Museum of the Gold Coast, in connexion with which a large archaeological museum is to be built next year in Accra, while museums at Kumasi and Tamale are planned. In the meantime the research museum at Legon, near Accra, has been opened to the public. The National Museum during the three years of its existence has accumulated many objects of interest; though very little systematic excavation has so far been attempted in the Gold Coast, the collections have twice outgrown the space allotted to them. The scope of the National Museum is wide: it is to illustrate what man has achieved in all Africa. The ancient civilizations of North Africa are treated so amply, in view of their known or suspected relations with West Africa, that there are many valuable exhibits of Greek, Roman, and Egyptian origin. Recent cultures of other parts of Africa are illustrated by works of artistic interest. The contents of the museum of Achimota School (consisting of some 5,000 objects of Gold Coast origin as well as material from Nigeria) were transferred to the Museum in 1953. Excavations in the Gold Coast have yielded a great quantity of Iron Age and Stone Age implements as well as baked-clay statuettes, some of them of distinct artistic merit. The museum has also been the recipient of gifts from English museums as well as from private collections.

\section{Pan-African Congress on Prehistory}

THE third meeting of the Pan-African Congress on Prehistory will be held in Livingstone, Northern Rhodesia, in July I955, at the invitation of the Northern Rhodesia Government, 